REVISTA DE DERECHO UNED, NÚM. 26, 2020

\title{
EL DERECHO DE LA LIBERTAD SINDICAL EN AMÉRICA LATINA "EL CASO COLOMBIA"
}

\author{
THE RIGHT TO FREEDOM OF ASSOCIATION IN LATIN \\ AMERICA “THE COLOMBIA CASE”
}

\begin{abstract}
ALFOnso ANTONio HeRnÁndez ORTIZ
Este trabajo se lleva a cabo dentro de las investigaciones correspondientes a la Eescuela de Doctorado en Derecho y Ciencias Sociales
\end{abstract}

Resumen: El trabajo persigue analizar la fragilidad del Estado de Derecho y con ella la impunidad a la violación de la Libertad Sindical en América Latina, abordando a profundidad el caso de Colombia, considerando la magnitud del problema en esta región. Si bien es cierto que estos países comparten al menos formalmente, los postulados de la Libertad Sindical desarrollados en el modelo de la OIT en sus Convenios Internacionales del Trabajo, especialmente en el $N^{\circ} 87$, sobre la Libertad Sindical y la Protección del Derecho de Sindicación, de 1948; y en el $\mathrm{N}^{\circ}$ 98, sobre el Derecho de Sindicación y de Negociación Colectiva, (de 1948), el continente americano presenta el mayor número de quejas por violaciones a la Libertad Sindical. De tal manera que el estudio describe el contexto de la crisis sindical que atraviesa América Latina, la problemática de la violación a la Libertad Sindical en Colombia, abordando el contexto legal y la realidad denunciada por tratadistas, organizaciones e instituciones internacionales. Se pretende concluir que las violaciones contra la vida, la libertad e integridad, cometidas contra sindicalistas en América Latina y en Colombia constituyen una grave vulneración a los derechos de Libertad Sindical y a derechos humanos fundamentales, consagrados y amparados por normas y pactos internacionales, por la Constitución Política y la ley. 
Abstract: The work seeks to analyze the fragility of the Rule of Law and with it the impunity for the violation of Freedom of Association in Latin America, addressing in depth the case of Colombia, considering the magnitude of the problem in this region. Although it is true that these countries share, at least formally, the postulates of Freedom of Association developed in the ILO model in their International Labor Conventions, especially in No. 87, on Freedom of Association and Protection of the Right to Organize , from 1948; and in $\mathrm{N}^{\circ}$ 98, on the Right to Organize and Collective Bargaining, (from 1948), the American continent presents the highest number of complaints for violations of Freedom of Association. In such a way that the study describes the context of the trade union crisis that Latin America is going through, the problem of the violation of Freedom of Association in Colombia, addressing the legal context and the reality denounced by international treaties, organizations and institutions. The aim is to conclude that the violations against life, liberty and integrity committed against trade unionists in Latin America and Colombia constitute a serious violation of the rights of Freedom of Association and fundamental human rights, enshrined and protected by international norms and covenants, by the Political Constitution and the law.

Palabras Claves: Libertad Sindical, Derechos Laborales; América Latina; Colombia.

Keywords: Freedom of Association, Labor Rights; Latin America; Colombia.

Sumario: 1. Introducción. 2. El contexto de la crisis sindical en América Latina. 3. Fundamentos Legales y Jurisprudenciales de la Libertad Sindical en Colombia. 4. Poder Jurídico vinculante de los Convenios de la O.I.T. 5. Legislación Laboral contraria a la Libertad Sindical. Conclusiones. Bibliografía.

Recepción original: 21-2-2020

Aceptación original: 16-6-2020

\section{INTRODUCCIÓN.}

El trabajo persigue desarrollar la situación que se presenta en América Latina ante la violación a Libertad Sindical, enfocándose fundamentalmente en el caso de Colombia, considerando que a pesar que haber transcurrido más de 65 años de vigencia de los Convenios números. 87 y 98 de la OIT, que consagran la Libertad Sindical 
en el derecho internacional, la humanidad debería estar cercana a la erradicación de su falta de reconocimiento y de los actos violatorios pero, lamentablemente, esto aún es bastante lejano de la realidad. Los avances que se han logrado, no han sido siempre sostenibles.

Asimismo, el estudio profundiza la vulnerabilidad que afecta a la mayor parte de las organizaciones sindicales latinoamericanas, considerando sus causas exógenas y causas endógenas, considerando según Sánchez-Rodríguez que la imposición de regímenes autoritarios, que en el pasado se implantaran en gran número de países, ha dejado secuelas jurídicas, institucionales y culturales que obstruyen o confrontan en algunos casos la vigencia y pleno ejercicio de la Libertad Sindical. Esta situación generó la fragilidad del Estado de Derecho y con ella la impunidad a la violación de los derechos laborales, situación que aún se observa en algunos países de la región, y que explica, entre otros, altas tasas de quejas en el Comité de Libertad Sindical.

En el Informe sobre violaciones a los derechos sindicales de la Confederación Sindical Internacional (CSI) del año 2013, que cubre 156 países, se señala que "Los sindicalistas han tenido que enfrentarse a la violencia en 24 de los 87 países (encuestados), considerando que no existen estadísticas que a nivel mundial nos muestren, la magnitud de las violaciones, sin embargo se afirma que del Continente Americano proviene el mayor número de Quejas por violación a la Libertad Sindical presentadas ante el Comité de Libertad Sindical del Consejo de Administración, predominando según registros que 18 sindicalistas han sido asesinados desde 2012 en Colombia”.

Las 5 categorías de violación a la Libertad Sindical denunciadas a través de las Quejas, son:

- La discriminación antisindical, con más del 35\% de incidencia en los agravios expresados y que algunas de sus manifestaciones más frecuentes son el despido, el acoso y hostigamiento, la violación al fuero sindical y la negativa al reintegro de los trabajadores despedidos aun a pesar de mediar disposición de autoridad competente.

- Los ataques a la vida, seguridad e integridad de las personas. Este tipo de violación se manifiesta a través del homicidio, las amenazas, las detenciones y la sujeción a juicios por la criminalización de la protesta.

- La obstaculización a la negociación colectiva. Esta violación puede darse tanto por restricciones normativas, es típico el 
caso en el sector público, como en la práctica por la negativa a negociar, el incumplimiento de lo negociado, etc.

- La injerencia. Esta forma de restringir la libertad y autonomía de las organizaciones sindicales se expresa de múltiples formas, como por ejemplo la sujeción de las elecciones sindicales a un ente público o el condicionamiento excesivo de lo que debe contener un estatuto sindical, pero también a través de medidas prácticas como la presión a renunciar al sindicato, el favoritismo, etc.

Por otra parte, la investigación señala que los infractores directos de la Libertad Sindical, son los empleadores y en muchos casos, son las entidades públicas las que con mayor frecuencia son denunciadas en las quejas presentadas ante la OIT. Esta situación abona a un fenómeno muy grave que es la impunidad y con ella, la fractura de la democracia y la cohesión social.

De igual forma se abordan los fundamentos legales y jurisprudenciales de la Libertad sindical en Colombia, fundamentando que si bien la OIT, hace parte del Bloque de Constitucional, debería ser mayor el compromiso del Estado colombiano en el cumplimiento de la normativa, ya que de igual forma, así lo reitera la Corte Constitucional colombiana, 2015, establecido en su orden legal y democrático del Estado.

Sin embargo, según lo planteado por el Colectivo de Abogados «José Alvear Restrepo» (2005) , señala que aun cuando Colombia ha ratificado los convenios 87 y 98 sobre Libertad Sindical mediante las leyes 26 y 27 de 1976, validación que implica que el Estado se comprometió frente a otros estados a darle aplicación a las normas sobre Libertad Sindical, designa una doble moral, porque en el seno de OIT el Estado recibe aplausos por acogerse a los convenios y, a nivel interno los desconoce y legisla contrariando sus postulados, convirtiéndose así en un transgresor de sus obligaciones como miembro de la OIT y demostrando que en las relaciones obrero - patronales el Estado interviene en favor del capitalismo, presentándose, de hecho una contradicción entre la legislación interna y el Derecho Internacional del Trabajo.

La puja de las organizaciones sindicales y la apertura de autoridades laborales, han desarrollado recientemente mecanismos tendientes a brindar una mayor y mejor atención a las violaciones a la Libertad Sindical, con resultados incipientes pero esperanzadores, como es el caso colombiano de la conformación tripartita 
de la Comisión Especial de Tratamiento de Conflictos ante la OIT (CETCOIT) instaurada por acuerdo del 31 de octubre de 2000, en la Comisión Permanente de Concertación de Políticas Salariales y Laborales (CPCPSL), es un organismo encargado de atender los conflictos suscitados en las materias reguladas por los Convenios 87, 98, 151 y 154 de la OIT, ratificados por Colombia. Este mecanismo está siendo objeto de atención en varios países de la región como son Guatemala y Panamá.

¿Por qué si la Libertad Sindical es un derecho humano, reconocido en todos los instrumentos internacionales (de la OIT, Organización de Naciones Unidas, Organización de Estados Americanos, etc.) así como en las constituciones políticas (habiendo siendo la primera de ellas la Mexicana 1917), su nivel de irrespeto es tan elevado? Sin duda que la respuesta no es unívoca, ni simple, pero entre los factores que podrían estar presentes podemos indicar a los siguientes: la debilidad de la institucionalidad democrática; el carácter marginal del Ministerio del Trabajo, entidad responsable del fomento y de las estrategias para la creación permanente de empleo estable y con las garantías prestacionales, salariales y de jornada laboral aceptada y suscrita en la Organización Internacional del Trabajo; la opinión fraguada en la opinión pública sobre el sindicalismo; la tolerancia o indiferencia ante las violaciones a los derechos sindicales; y, por tanto, la evidente debilidad en la cultura de los derechos humanos.

Finalmente, a través de esta investigación se señalan las causas y consecuencias de la violación y el nivel de cumplimiento de la garantía a la Libertad Sindical en América Latina, permitiendo contrastar lo establecido en los Convenios Internacionales, los fundamentos constitucionales e instrumentos normativos que rigen la Libertad Sindical; divisando las graves consecuencias que genera la violación del derecho a la Libertad Sindical para los trabajadores, la democracia, el Estado de Derecho y de Justicia en el continente y su correspondencia con la experiencia colombiana, desnudando así una realidad innegable: Colombia sigue siendo uno de los países más peligrosos para el ejercicio de la actividad sindical en el mundo.

\section{EL CONTEXTO DE LA CRISIS SINDICAL EN AMÉRICA LATINA.}

Según Zapata (2003), el sindicalismo latinoamericano, después de haber desempeñado un importante papel en la organización de los trabajadores en América Latina, en sectores como la minería, la 
industria manufacturera y la burocracia pública, de haber establecido estándares laborales y la negociación de contratos colectivos de trabajo, de haber desarrollado canales de participación política y haber contribuido al desarrollo de la democracia, atraviesa por una crisis cuyas dimensiones de esta dificultades guardan relación con las profundas transformaciones económicas y sociales que han afectado a los países latinoamericanos desde 1982 y por la modificación del contenido y de la forma de operar de los sistemas políticos y de la redefinición de la democracia.

Considera el autor en cita, que también tienen que ver los cambios de las estructuras ocupacionales y el paso al predominio de la economía de los servicios. El impacto de estas transformaciones ha tenido como resultado que el movimiento obrero latinoamericano dejó de cumplir con las funciones que jugaba en un continente fuertemente marcado por las características de los estados naciones que se formaron en el siglo XIX y de las estructuras políticas que se derivaron de los cambios ocurridos en la primera mitad del siglo XX en países como Argentina, Brasil, México, o Chile.

La democracia política dejó de ser un reflejo de las estructuras sociales y las estructuras ocupacionales dejaron de estar centradas en las actividades manufactureras, los servicios de utilidad pública (electricidad, gas, agua) y la burocracia estatal. Por lo cual, son estas cuestiones las que hay que considerar en detalle, al analizar la crisis del sindicalismo, de igual forma es menester colocar en el contexto la pérdida progresiva de aquellos fundamentos económicos y sociales que dieron razón de ser a esta forma de organización de los trabajadores. En efecto, la crisis no resulta sólo de procesos económicos y sociales coyunturales sino que tienen también que ver con la desaparición de las condiciones políticas e ideológicas que le dieron sentido.

Dentro del análisis del sindicalismo en América Latina, los antecedentes mencionados son importantes porque definen el marco general dentro del cual deben analizarse los procesos concretos que han tenido lugar en la región desde 1982, los cuales han repercutido sobre las dos fuentes de poder del sindicalismo, las ligadas al control del proceso de trabajo y de los mercados de trabajo y por otra parte las ligadas el acceso al poder político y al Estado.

Sin embargo, para enmarcar esta discusión no basta con definir el marco general. Es necesario presentar también los aspectos coyunturales ligados a las dos transiciones por los cuales ha transitado esta región del mundo en los últimos veinte años: por un lado, 
la transición entre modelos de acumulación desde el patrón de desarrollo de la industrialización por sustitución de importaciones (ISI) al tipo de desarrollo de la transnacionalización del mercado interno (TMI) (Reinhard-Peres, 2000) y, por otro lado, la transición entre otros estándares de dominación política, desde los regímenes dictatoriales encabezados por los militares a las "nuevas" democracias actuales. En la transición entre modelos de desarrollo es importante tener presente que se trata de un tránsito entre un esquema en el que el mercado interno y el capital nacional jugaron un papel central a un paradigma en el que el comercio externo y el capital extranjero constituyen los mecanismos principales de dinamismo económico, lo que no implica que en la ISI el capital extranjero no haya desempeñado un papel importante en el financiamiento de ciertos sectores de la industria pesada (siderurgia por ejemplo) ni que en el TMI capital nacional no se haya involucrado en la privatización de las empresas de propiedad estatal (como en la electricidad o en las telecomunicaciones). No obstante, es importante recalcar la centralidad del capital nacional, privado público, durante la ISI y el peso del capital financiero internacional en el modelo de la TMI.

En esta transición también es importante señalar la fuerte disminución del papel del Estado y de la soberanía financiera junto con fuertes bloqueos al crecimiento económico y a la movilidad social. El paso del modelo de desarrollo de la ISI al TMI implica también la separación progresiva de la economía y de los marcos institucionales y políticos que la regulaban. Por otra parte, la transición política entre el autoritarismo y los regímenes re-democratizados (en los países que sufrieron la dominación militar) implica el restablecimiento o el establecimiento de los mecanismos de la democracia representativa y por lo tanto la diferenciación entre sociedad civil, sistema político y Estado (Touraine, 1995), los cuales estaban confundidos bajo la dominación estatal en los regímenes autoritarios o dictatoriales.

En tal sentido, según el análisis expuesto por Zapata, de la crisis del sindicalismo en América Latina debe encuadrarse en (a) el marco general de los antecedentes de lo que son las bases del poder sindical y (b) en el contexto de las dos transiciones antes mencionadas. Ambas dimensiones pueden contribuir a comprender mejor las razones por las cuales el sindicalismo latinoamericano se encuentra hoy en crisis. Siendo estos dos elementos los temas específicamente ligados a la crisis del sindicalismo latinoamericano contemporánea.

En suma, los problemas en el ejercicio de los derechos colectivos, la debilidad de los sindicatos o su falta de interés en los sectores más vulnerables, no son exclusivos de los países más pequeños, 
de menores ingresos o con tasas muy bajas de afiliación ni se deben exclusivamente a las reformas neoliberales o a deficiencias en implementación, en tanto subsisten fuertes problemas en los diseños legales y restricciones derivadas de las formas de inserción en la economía mundial (Bensusán, 2010; Vega Ruiz; 2005 y Anner, 2008) . Estos diseños han preservado un régimen sindical que sigue dejando amplios márgenes para la intervención estatal en la vida sindical, en los países de tradición corporativa o abren oportunidades significativas a los empresarios para impedir la organización, lo que de una u otra forma expresaría la desconfianza y el temor a la acción colectiva (Vega Ruiz, 2004).

Además, estos esquemas crean los canales institucionales adecuados en el seno de los sindicatos para ampliar la participación de los trabajadores en el diseño de estrategias de defensa de sus intereses. Así, junto a los problemas pendientes de la democratización política, la reforma del Estado y la adopción de estrategias de desarrollo junto a las políticas de distribución de los resultados que permitan cerrar las brechas de la desigualdad en la región, está el de la falta de representación de amplios sectores de la sociedad que viven de su trabajo, sean o no asalariados, y requieren hoy más que nunca de mecanismos de protección de sus ingresos y condiciones de vida. Es claro que sin esta representación no se cumplirán siquiera los requisitos mínimos de la democracia ni se ejercerá contrapeso alguno a los efectos más perjudiciales del proceso de globalización.

La dimensión referida al mercado laboral, tiene cada vez un peso mayor, pues fenómenos como la flexibilidad, externalización o tercerización, el uso excesivo de las formas de contratación temporal y las condiciones de temor e inseguridad que condicionan el ejercicio de la libertad para sindicalizarse y mantenerse organizado. Otros factores internos que también podrían tener un peso en ese análisis son el modelo de organización prevaleciente, la dinámica intraintersindical, asociada a la naturaleza de su vinculación con la sociedad, los partidos políticos y el gobierno.

Para Besunsán, citado por Marín Boscán (2014), al estudiar la efectividad de la legislación laboral en América Latina, destaca entre algunos aspectos, que se observan insuficiencias en la protección de los trabajadores, en las nuevas condiciones derivadas de la globalización, que se suman a las que existían históricamente en la región, debido a la inefectividad de las normas y la necesidad de contar con sindicatos con poderes reales, capaces de ejercer un contrapeso a las políticas empresariales, y a la vez compartir los retos que impone la competitividad. 
De igual forma, Marín Boscán (2013), cita en su trabajo el Informe sobre las Violaciones de los Derechos Sindicales de 2012, en el cual se destaca en relación a América, que el continente continúa siendo escenario adverso para la vigencia de las libertades sindicales en 2011. Se hace constar en este informe, que la violencia y la impunidad de crímenes contra sindicalistas, fue el factor común de muchos de los países del continente, presentando en este sentido las cifras más elevadas del mundo.

Desde la opinión de Martínez y Vega (2001), los países andinos se apartan mucho de ser un paradigma en el cumplimiento normativo internacional como lo demuestra, de forma fehaciente, el número de observaciones y solicitudes directas pendientes de la Comisión de Expertos en Aplicación de Convenios y Recomendaciones de la OIT (CEACR), así como el número de quejas presentadas ante el Comité de Libertad Sindical (CLS) por inobservancia de los Convenios relativos a Libertad Sindical.

Asimismo, los autores ut supra platean que todos los países son objeto de observaciones a la CEACR por incumplimiento de los Convenios ratificados en materia de Libertad Sindical, siendo repetidos los comentarios pendientes por falta de solución, situación que, en muchos de los casos, se ha mantenido por largos años. En un repaso rápido, los incumplimientos en materia de legislación resultan similares, si bien presentan, a menudo, un tenor diferente siguen produciendo, a mediano plazo, comentarios similares y, en todo caso, el descontento de las organizaciones sindicales que mantienen (incluso incrementan) el número de quejas presentadas ante el Comité de Libertad Sindical.

Por su parte Uriarte Ermida (2012), plantea que la debilidad que afecta a la mayor parte de las organizaciones sindicales latinoamericanas tiene causas exógenas y causas endógenas, es decir, causas que le vienen impuestas desde fuera y otras que son propias de algunas características del sindicalismo de la región. Entre las causas externas o exógenas, debe mencionarse en primer lugar, claro está, la reglamentación limitativa del sindicato y el control político que sobre él tiende a ejercer el Estado. También debe incluirse una política económica adversa, neoliberal, que se generalizó en la mayor parte de nuestros países en los años ochenta y noventa. En tercer lugar, una estructura inconveniente, impuesta legislativamente, a lo que debe agregarse, en cuarto término, los procesos de descentralización empresaria que, sumados a la estructura sindical descentralizada, terminan segmentando al colectivo de los trabajadores que debería ser la base sindical. 
Precisa el autor en cita, que no todo el mal viene de afuera. La debilidad sindical también tiene causas propias, internas o endógenas. Por ejemplo, el divisionismo y la atomización sindical Hay países pequeños en los que existen entre cinco y diez centrales sindicales. Se llega a contabilizar más de veinte sindicatos en una misma empresa. El denominado "paralelismo sindical" es una realidad frecuente en muchos de nuestros países. En tal panorama, no extraña que la mayor parte de los sindicatos de la región tengan una baja representatividad, lo que supone como necesaria consecuencia un menor poder (ante los empleadores, ante las autoridades y ante los propios trabajadores). En otros casos, aunque claro que no en todos, se verifica una dependencia política del sindicato, sea del Gobierno, sea del partido. Ello puede responder a razones ideológicas, claro está, pero en ocasiones también puede deberse a la propia debilidad del sindicato, que solo puede sostenerse o alcanzar ciertos logros, a costa de una identificación política que no le sería indispensable si tuviera mayor poder propio.

\section{FUNDAMENTOS LEGALES Y JURISPRUDENCIALES DE LA LIBERTAD SINDICAL EN COLOMBIA.}

En lo que respecta al tema en cuestión relativo al estudio de la Libertad Sindical en Colombia, su problemática y la jurisprudencia desde la óptica de Buitrago y Restrepo (2015), quienes abordan el tema parten de la premisa que en Colombia, mediante el desarrollo jurisprudencial de la Corte Constitucional, como única intérprete autorizada de la Carta Magna, se considera la Libertad Sindical como un derecho fundamental, tal como aparece estipulado en el artículo 39 de la Carta Política Colombiana;

Artículo 39. Los trabajadores y empleadores tienen derecho a constituir sindicatos o asociaciones, sin intervención del Estado. Su reconocimiento jurídico se producirá con la simple inscripción del acta de constitución. La estructura interna y el funcionamiento de los sindicatos y organizaciones sociales y gremiales se sujetarán al orden legal y a los principios democráticos. La cancelación o la suspensión de la personería jurídica sólo procede por vía judicial. Se reconoce a los representantes sindicales el fuero y las demás garantías necesarias para el cumplimiento de su gestión. No gozan del derecho de asociación sindical los miembros de la Fuerza Pública.

De igual forma según los Convenios 87 y 98 de la Organización Internacional del Trabajo integrados al orden interno con rango de normas constitucionales, en virtud del artículo 93 de la Constitución Política de Colombia: 
Artículo 93; Los tratados y convenios internacionales ratificados por el Congreso, que reconocen los derechos humanos y que prohíben su limitación en los estados de excepción, prevalecen en el orden interno. Los derechos y deberes consagrados en esta Carta, se interpretarán de conformidad con los tratados internacionales sobre derechos humanos ratificados por Colombia. El Estado Colombiano puede reconocer la jurisdicción de la Corte Penal Internacional en los términos previstos en el Estatuto de Roma adoptado el 17 de julio de 1998 por la Conferencia de Plenipotenciarios de las Naciones Unidas y, consecuentemente, ratificar este tratado de conformidad con el procedimiento establecido en esta Constitución. La admisión de un tratamiento diferente en materias sustanciales por parte del Estatuto de Roma con respecto a las garantías contenidas en la Constitución tendrá efectos exclusivamente dentro del ámbito de la materia regulada en él.

A lo anterior, la Corte Constitucional añade un argumento suplementario; que si Colombia ha suscrito esos tratados, entonces debe respetar lo que ellos establecen, pues el país se comprometió a cumplirlos de buena fe. Concluyéndose entonces, que "la interpretación y aplicación de los derechos laborales en Colombia, debe consistir en la integración de las normas constitucionales y los tratados internacionales ratificados sobre la materia.

Tal y como lo expresa la Carta Política colombiana, la Libertad Sindical comprende un complejo conjunto de garantías conexas. En primer término, el derecho de asociación sindical (artículo 39 de la Constitución Política), el derecho a negociar las condiciones laborales, bajo los parámetros establecidos en la Constitución y la Ley, y la posibilidad de iniciar una huelga, respetando también parámetros impuestos por el orden Superior

Ahora bien, frente al derecho de asociación sindical, la Corte Constitucional ha sostenido en su Sentencia T-441/92 que la libertad de asociación sindical comprende tres enfoques, a saber:

a) Libertad individual de organizar sindicatos, cuyo pluralismo sindical está consagrado en el artículo $2^{\circ}$ del Convenio 87 de la Organización Internacional del Trabajo;

b) Libertad de sindicalización (o sindicalización), ya que nadie puede ser obligado a afiliarse o a desafiliarse a un sindicato; en palabras del artículo 358 del Código Sustantivo de Trabajo, inciso $1^{\mathrm{o}}$ : «Los sindicatos son asociaciones de libre ingreso y de retiro de los trabajadores";

c) Autonomía sindical que es la facultad que tiene la organización sindical para crear su propio derecho interno, para organizar- 
se, tal como lo dispone el artículo $3^{\circ}$ del Convenio 87 de la OIT." (Colombia, Corte Constitucional, 192). De otro lado, la no injerencia del Estado (y particularmente de la administración) en las decisiones de los Sindicatos es un principio cardinal del derecho a la asociación sindical, precisado especialmente en el Convenio 87 de la OIT.

De igual forma, el Convenio 98 de la misma Organización prevé diversas reglas asociadas al principio de no discriminación. Específicamente, prohíbe a los empleadores:

a) sujetar el empleo de un trabajador a la condición de que no se afilie a un sindicato o a la de dejar de ser miembro de un sindicato;

b) despedir a un trabajador o perjudicarlo en cualquier otra forma a causa de su afiliación sindical o de su participación en actividades sindicales fuera de las horas de trabajo o, con el consentimiento del empleador, durante las horas de trabajo.

En suma, se puede afirmar sin lugar a dudas y retomando la postura del Constitucional colombiano, que el derecho sindical es a la vez un derecho constitucional individual de los trabajadores que son titulares del mismo, y un derecho constitucional colectivo, cuyo titular es el Sindicato.

Así mismo es importante destacar que en la doctrina internacional y colombiana hay cuatro (4) tipos de sindicatos:

a) De empresa, si están formados por individuos de varias profesiones, oficios o especialidades, que prestan sus servicios en una misma empresa, establecimiento o institución.

b) De industria o por rama de actividad económica, si están formados por individuos que prestan sus servicios en varias empresas de la misma industria o rama de actividad económica.

c) Gremiales, si están formados por individuos de una misma profesión, oficio o especialidad.

d) De oficios varios, si están formados por trabajadores de diversas profesiones, disímiles o inconexas.

Estos últimos sólo pueden formarse en los lugares donde no haya trabajadores de una misma actividad, profesión u oficio en número 
mínimo requerido para formar uno gremial, y solo mientras subsista esta circunstancia

Considerando, la Libertad Sindical como derecho fundamental, tiene reconocimiento como derecho humano, universal, a todas las personas que tengan la condición de trabajadores para que puedan agruparse en organizaciones que representen los intereses que son comunes a todas ellas en el ámbito laboral.

No obstante lo anterior, cabe mencionar que la Libertad Sindical, contenida en los mencionados instrumentos internacionales de la OIT, hace parte del Bloque de Constitucional, lo que refuerza el compromiso estatal de Colombia en el cumplimiento de las normativas de la máxima organización del trabajo en el plano internacional, y lo dota de la fuerza vinculante propia del bloque de constitucionalidad, así lo reitera la Corte Constitucional colombiana, 2015.

El alcance del derecho de asociación, que comporta en sí mismo a la Libertad Sindical, fija su alcance conforme el contenido del Convenio 187 de la Organización Internacional del Trabajo OIT y los tratados internacionales sobre derechos humanos del trabajo, y en tal sentido, se establece en su articulado la prohibición a los Estados parte, de intervenir para limitar el ejercicio legal del derecho de asociación, entre otros.

De tal manera, es necesario aclarar que a pesar de la protección y el carácter de derecho fundamental que se endilga a la Libertad Sindical, la misma no tiene carácter absoluto, y en la medida en que es la propia Carta Política establece como limitación, concretable por el legislador, que la estructura interna de los sindicatos y organizaciones sociales y gremiales se sujetarán al orden legal y a los principios democráticos y que, los Convenios Internacionales sobre derechos humanos autorizan que por vía legislativa puedan imponerse restricciones a los derechos, en cuanto ellas sean necesarias, mínimas, indispensables y proporcionadas a la finalidad que se persiga, para garantizar la seguridad nacional, el orden, la salud o moral públicos, los derechos y deberes ajenos y, en general, el cumplimiento de cualquier finalidad que se estime esencialmente valiosa.

Por lo tanto, se advierte, que las aludidas restricciones o limitaciones no pueden, en modo alguno, afectar lo que se considera el núcleo esencial del derecho a la Libertad Sindical, de modo que la desnaturalicen o impidan su normal y adecuado ejercicio.

En consecuencia, si bien la Libertad Sindical persigue una protección reforzada por parte del constituyente y del legislador colom- 
biano, la misma no es absoluta y contiene unos límites establecidos por el orden legal y democrático del Estado, sin que tales límites ejerzan restricciones al ejercicio del derecho de Libertad Sindical, ni menoscaben su contenido.

El Estado colombiano aprobó la Ley 26 de 1976 (septiembre 15) en cumplimiento del Convenio número 87 adoptado por la Trigésima Primera Reunión de la Conferencia General de la Organización Internacional del Trabajo (1948), relativo a la Libertad Sindical y a la protección del derecho de sindicalización.

En el artículo 38 de la Constitución política se reconoce la Libertad Sindical y a la protección del derecho de sindicalización. A su vez, la Corte Constitucional colombiana dispuso en la sentencia $\mathrm{N}^{\circ}$ 441/92 que el derecho de asociación sindical es un derecho subjetivo el cual tienen la función estructural que desempeñar, pues constituye la manera de realizar y reafirmar el estado social y democrático de derecho, permitiendo este derecho que el individuo se integre a los diferentes grupos, y no es un derecho aislado y particular, sino un fenómeno social fundamental en una sociedad democrática; además, debe ser reconocido por todas las ramas y órganos del poder público. Asimismo, tiene un carácter relacional porque aparece por un lado como un derecho individual y por el otro se ejerce cuando haya otros ciudadanos que este dispuestos a ejercitar ese derecho, y cuando se dé esta condición de voluntades se forma una persona colectiva (Colombia, Corte Constitucional, 1992).

Si bien, el derecho al trabajo es un derecho fundamental el cual se debe asegurar a todos los integrantes de la sociedad, en un Estado social de derecho, que garantice un orden político, económico y social justo. Este derecho al estar inmerso dentro de la Constitución Nacional Colombiana, se encuentran dentro del mismo los siguientes derechos: la dignidad humana en conexión con el artículo 25 de la Carta Política Colombiana que dispone el derecho al trabajo digno, siendo un derecho de todas las personas y un deber del Estado su garantía.

Artículo 25. El trabajo es un derecho y una obligación social y goza, en todas sus modalidades, de la especial protección del Estado. Toda persona tiene derecho a un trabajo en condiciones dignas y justas.

Dentro de esto se encuentra la protección al derecho de asociación sindical. La Corte constitucional ha establecido esa libertad de asociación de los trabajadores como un derecho fundamental, consagrado en el artículo 38 de la Carta Magna, en donde se garantiza el 
derecho de libertad de asociación sindical para ejercer diferentes actividades que las personas tienen dentro de la sociedad.

El artículo 53 del Texto Fundamental establece que los Convenios Internacionales del trabajo debidamente ratificados, hacen parte de la legislación interna colombiana;

Artículo 53. El Congreso expedirá el estatuto del trabajo. La ley correspondiente tendrá en cuenta por lo menos los siguientes principios mínimos fundamentales: Igualdad de oportunidades para los trabajadores; remuneración mínima vital y móvil, proporcional a la cantidad y calidad de trabajo; estabilidad en el empleo; irrenunciabilidad a los beneficios mínimos establecidos en normas laborales; facultades para transigir y conciliar sobre derechos inciertos y discutibles; situación más favorable al trabajador en caso de duda en la aplicación e interpretación de las fuentes formales de derecho; primacía de la realidad sobre formalidades establecidas por los sujetos de las relaciones laborales; garantía a la seguridad social, la capacitación, el adiestramiento y el descanso necesario; protección especial a la mujer, a la maternidad y al trabajador menor de edad. El estado garantiza el derecho al pago oportuno y al reajuste periódico de las pensiones legales. Los convenios internacionales del trabajo debidamente ratificados, hacen parte de la legislación interna. La ley, los contratos, los acuerdos y convenios de trabajo, no pueden menoscabar la libertad, la dignidad humana ni los derechos de los trabajadores.

Y estos fundamentos del 39 de la Constitución se encuentran en el Pacto Internacional de Derechos Económicos, Sociales y Culturales, ratificado por Colombia mediante la Ley 64 de 1968.

De conformidad con la jurisprudencia respecto a la libertad de asociación sindical la Corte Constitucional ha establecido que este derecho comprende:

a) el derecho a vincularse a organizaciones permanentes que les otorguen una identidad común, y que tienen por objetivos la defensa de intereses comunes, siendo la vinculación voluntaria;

b) la libertad de participar en tales organizaciones como personas jurídicas, sin la intervención o restricción del Estado;

c) la libertad de determinar el objeto, los requisitos para su admisión, estatutos, permanencia, retiros, manejo de recursos y en general todos los aspectos que se consideren necesarios para el buen funcionamiento de la asociación siempre con sujeción a los principios democráticos; 
d) la imposibilidad de cancelación de su o suspensión de su personería jurídica;

e) la autonomía que tienen los sindicatos como asociaciones de empleadores de pertenecer a federaciones y confederaciones de carácter nacional como internacional.

En Colombia se ha reconocido a través de la jurisprudencia constitucional el derecho de buscar la protección jurídica para la protección de los derechos fundamentales a través de la acción de tutela. Así las cosas, no sólo las personas naturales sino también las jurídicas en cuanto a la proyección del ser humano tienen derechos fundamentales, tales como la propiedad, el debido proceso, el derecho de petición, el derecho de acceso a la información.

En consecuencia, las personas naturales y jurídicas poseen derechos y obligaciones dentro del sistema jurídico colombiano. La titularidad de la libertad de expresión es reconocida por la Corte Constitucional a las personas naturales como jurídicas, este derecho se hace extensible a los sindicatos y sus miembros. Los sindicatos ejercen el derecho a la libertad de expresión en cuanto son los encargados de difundir las ideas y opiniones en el ámbito laboral, en el marco de las negociaciones colectivas, por medio de cualquier medio que escojan ya sea escrito u oral, siendo un derecho que tiene dos dimensiones: el derecho de los sindicatos a difundir la información y transmitir sus opiniones, como el derecho de los trabajadores a recibir la información sin obstáculos.

Entonces, en la negociación colectiva cuando el empleador interfiere en la misma y tiene la posibilidad de restringir el derecho a la libertad de expresión, como elemento fundamental del sindicato una acción inconstitucional y desproporcionada, que vulnera los derechos de asociación sindical y negociación colectiva.

Así pues, la Corte Constitucional colombiana ha reiterado el derecho de las personas jurídicas de reclamar el amparo de sus derechos fundamentales a través de la acción de tutela. Entonces, las personas jurídicas son titulares de derechos constitucionales fundamentales en tanto, la esencialidad de esto gira en torno a la tutela de los derechos de las personas naturales asociadas, cuando las personas jurídicas son titulares de derecho fundamentales no porque sustituyan a sus miembros, sino que lo son por sí mismas.

Esto ha sido reiterado en la Sentencia de la Corte Constitucional T-063 de 2014, en el sentido de los derechos sindicales y la posibilidad que la persona jurídica ejerza la acción de tutela con el fin de 
proteger sus derechos y el de sus afiliados, siendo necesario analizar que su legitimidad dependerá de si se pretende proteger los derechos colectivos o aquellos del trabador desde su individualidad.

Cuando se pretende salvaguardad los derechos de sus afiliados, irán ligados al sindicato, porque independientemente del individuo, lo que suceda afectará a todos sus miembros y por esto estará facultada la persona jurídica por conducto de su representante legal para acudir al amparo constitucional. A diferencia de cuando es una protección individual del trabajador, quien busca obtener beneficios individuales que no vinculan al sindicato, es él mismo, como persona natural quien debe interponer la acción ya sea en nombre propio, o a través de apoderado. Sin que se involucre al sindicato o sus intereses.

Dentro de los derechos que se tienen en la asociación sindical es el derecho al reconocimiento de los permisos sindicales porque sin este, se estaría restringiendo el derecho de asociación sindical. Esto permite facilitar el desempeño de las uniones propias de quienes promueven y protegen los intereses de la organización colectiva y de sus miembros. Es deber de Estado otorgar a los sindicatos y en especial a quienes ejercen labores representativas, de mecanismos que permitan mostrar su visibilidad y gestión, pues de otra manera no se estaría permitiendo su funcionamiento.

Así, es un derecho fundamental que tienen las personas que participan y tienen representación en los sindicatos, a gozar de los permisos sindicales como garantía para su ejecución. Siendo un deber del Estado no interferir en su funcionamiento de manera libre y voluntaria, proporcionando la efectiva realización de valores fundamentales de la sociedad como el trabajo, la justicia social, la paz, la libertad y la convivencia (T-063 de 2014.). No basta con el simple reconocimiento del derecho de la organización sindical sino que es de vital importancia para su funcionamiento, la dotación de garantías que hagan visible su gestión.

Esto ha sido reconocido en el artículo 39 de la Constitución Política colombiana que se denomina "garantías necesarias para el cumplimiento de la gestión de los representantes sindicales".

En consecuencia, en diferentes casos analizados por la Corte Constitucional se ha conocido el amparo de los derechos de los sindicatos, porque estos son legítimos para asumir su propia defensa como trabajadores que los integran.

Los sindicatos están legitimados para instaurar acción de tutela de conformidad con los artículos 86 de la Constitución Nacional de 
Colombia; y 10 del Decreto 2591 de 1991, norma que dispone que la tutela puede ser presenta por el afectado o quien actúe en su nombre o lo represente. En consecuencia, el juez de tutela será competente para conocer y decidir las relaciones entre trabajadores o sindicatos, y de empleadores en el caso que se presente vulneración a los derechos fundamentales.

Artículo 86. Toda persona tendrá acción de tutela para reclamar ante los jueces, en todo momento y lugar, mediante un procedimiento preferente y sumario, por sí misma o por quien actúe a su nombre, la protección inmediata de sus derechos constitucionales fundamentales, cuando quiera que éstos resulten vulnerados o amenazados por la acción o la omisión de cualquier autoridad pública. La protección consistirá en una orden para que aquel respecto de quien se solicita la tutela, actúe o se abstenga de hacerlo. El fallo, que será de inmediato cumplimiento, podrá impugnarse ante el juez competente y, en todo caso, éste lo remitirá a la Corte Constitucional para su eventual revisión. Esta acción solo procederá cuando el afectado no disponga de otro medio de defensa judicial, salvo que aquella se utilice como mecanismo transitorio para evitar un perjuicio irremediable. En ningún caso podrán transcurrir más de diez días entre la solicitud de tutela y su resolución. La ley establecerá los casos en los que la acción de tutela procede contra particulares encargados de la prestación de un servicio público o cuya conducta afecte grave y directamente el interés colectivo, o respecto de quienes el solicitante se halle en estado de subordinación o indefensión.

El derecho de asociación sindical faculta a los trabajadores para constituir organizaciones que consideren pertinentes para el ejercicio de este derecho, y afiliarse a las federaciones y confederaciones que aglutinan sindicatos, con el fin de cumplir los estamentos dispuestos de los sindicatos, teniendo las organizaciones sindicales la autonomía para la redacción de sus propios estamentos y estatutos, eligen a sus representantes, organizar las actividades a ejecutar, todo esto sin que el Estado pueda intervenir.

Unas de las consecuencias que se derivan del derecho a la Libertad Sindical es la garantía de un derecho de estabilidad laboral reforzada, para algunos trabajadores que ejercen funciones esenciales dentro del sindicato. Así, sus contratos no pueden darse por terminados por el empleador sin una justa causa, reconocida previamente por un juez laboral. Este derecho de Libertad Sindical se establece con el fin de proteger el sindicato antes que como un beneficio individual del aforado.

Esto se explica porque el derecho de asociación individual es un derecho constitucional que tienen los trabajadores que son titulares del mismo, pero a la vez, existe un derecho colectivo en el cual es ti- 
tular el sindicato. Así que cuando un empleador acude a la terminación del contrato de trabajo despide sin justa causa para afectar el derecho de Libertad Sindical, es claro que el objetivo primario de esto es debilitar al sindicato.

De conformidad con la jurisprudencia colombiana, en el evento en que despida a un miembro del sindicato aforado sin respeto por el debido proceso sindical, el despido es ineficaz, posteriormente dará lugar al reintegro del afectado, teniendo que pagarle los salarios y prestaciones que dejó de percibir, siendo esto independientemente de las sanciones que el legislador ha dispuesto en materia penal y pecuniaria para la protección del derecho de asociación sindical.

\section{PODER JURÍDICO VINCULANTE DE LOS CONVENIOS DE LA O.I.T.}

En materia Laboral, Colombia pertenece a la OIT desde el año 1919, y por consiguiente todos los tratados y Convenios que ha desarrollado la OIT deben ser presentados para incorporarlos a la legislación nacional, y desarrollados en pro de mantener armonía jurídica entre lo preceptúalo por el organismo internacional y la realidad del país.

$\mathrm{Al}$ respecto entonces tenemos, que para el caso colombiano «los tratados internacionales de la OIT deben ser celosamente cumplidos y desarrollados, pues además de ser votados favorablemente por el gobierno colombiano, por mandato de su normatividad positiva se integran a la legislación, bien sea como normas de aplicación supletoria cuando no han sido convertidos en leyes, o con el mismo alcance de éstas cuando han sido ratificados» Colectivo de Abogados «José Alvear Restrepo»(2005).

Es pues, de carácter general que los Pactos ratificados por Colombia se apliquen a la normatividad existente como leyes generales o normas supletivas, y esta aplicación inmediata de tales Pactos o Convenios proviene del carácter constitucional que tiene la celebración de Convenios y que se enmarcan dentro de los artículos 9 y 53 de la Constitución Política:

Artículo 9: Las relaciones exteriores del Estado se fundamentan en la soberanía nacional, en el respeto a la autodeterminación de los pueblos y en el reconocimiento de los principios del derecho internacional aceptados por Colombia. 
$\mathrm{Al}$ respecto la jurisprudencia colombiana, en la Sentencia de la Corte Constitucional No. C-276/93 ha suscrito:

«En el mundo moderno y contemporáneo, el equilibrio jurídico internacional parte del supuesto de que los órdenes internos de los Estados no son absolutos, ya que así como existe un interés general en el seno de cada uno de ellos, igualmente hay un interés general internacional, fundado en el bien común universal. Es éste interés el que busca realizarse mediante los pactos o tratados que se celebren en virtud del ejercicio de la soberanía, como atributo propio de cada uno de los Estados; el compromiso internacional es, así, un acto de soberanía del Estado que se vincula, es decir, se trata de la expresión de la voluntad independiente de cada Estado que pretende comprometerse como un ente jurídico en el plano internacional.

"En otras palabras, el pacto internacional es, como se ha dicho, una manifestación de la soberanía del Estado, un ejercicio de soberanía que trae como consecuencia la responsabilidad internacional. Si en el plano del hombre hay responsabilidad con fundamento en la libertad, en el plano internacional hay responsabilidad con fundamento en el ejercicio de la soberanía, pues el Estado que se compromete ha ejercido para ello su autodeterminación... «

El artículo 53 de la Constitución Colombiana, en su inciso 3 dice:

"Los convenios internacionales de trabajo debidamente ratificados hacen parte de la legislación interna"

Con esto se comprende que el carácter constitucional que tienen los tratados internacionales hace prever el respeto hacia los mismos dentro de la legislación interna de cada Estado parte del tratado.

Sobre los tratados y Convenios de la OIT tenemos, que al adherirse a la OIT todo miembro se ha comprometido a respetar un cierto número de principios, incluidos en los principios de la Libertad Sindical, que se ha convertido en una regla de derecho consuetudinario por encima de los Convenios.

Así mismo, se tiene que los convenios deben ser aplicados inmediatamente, una vez ratificados sin necesidad de medidas complementarias.

Los convenios una vez son suscritos aprobados y ratificados en forma regular por el Estado colombiano, conservan su vigencia y obligan al Estado en general y al ejecutivo en particular, aún en estados de excepción. Es conveniente insistir en que la Constitución Colombiana, no autoriza al ejecutivo a suspender los Convenios y los Tratados durante la vigencia del régimen de excepción, y que las leyes aprobatorias de Tratados y Convenios internacionales tienen jerarquía constitucional. 
En el caso de Colombia, según la jurisprudencia, de la Corte Constitucional Sentencia C-562 de octubre 22/92.

«un Convenio internacional del trabajo no vincula a un Estado sino hasta cuando lo ratifica. Ratificación que no tiene el significado y alcance que se ha dado a esta figura jurídica en el derecho internacional. En efecto; los Convenios de la OIT, desde el punto de vista internacional carecen formalmente de ratificación, pues solamente se requiere de la información a su director general sobre la aprobación del mismo por parte de la autoridad legislativa interna, en el caso de Colombia del Congreso de la República...»

Todo lo anterior, no hace más que ratificar la importancia de los Convenios de la OIT firmados por Colombia, así como de los demás tratados internacionales que sobre la Protección de Derechos Económicos y Sociales deben prevalecer en las legislaciones internas como mecanismos que impidan la creciente pauperización de la clase trabajadora.

Al respecto cabe anotar, que sobre la Libertad Sindical el Comité de Libertad Sindical ha tratado el asunto en los Convenios No. 87 y 98; el primero relativo a la libertad y protección al derecho de sindicalización y el segundo relativo al derecho de sindicalización y negociación colectiva, se deben resaltar los siguientes aspectos:

- Un movimiento sindical realmente libre e independiente solo puede desarrollarse dentro del respeto a los Derechos Humanos.

- El Comité de Libertad Sindical, ha indicado que no puede desarrollarse un movimiento sindical libre dentro de un régimen que no garantice los derechos fundamentales, en especial el derecho de los trabajadores sindicalizados a reunirse en los locales sindicales, el derecho de libre opinión verbal y escrita y el derecho de los trabajadores sindicalizados a contar en caso de detención con las garantías de un procedimiento judicial regular incoado lo antes posible.

- La Conferencia Internacional del Trabajo señaló que el derecho de reunión, la libertad de opinión y expresión y, en particular, el de derecho a no ser molestado por sus opiniones y el de buscar y recibir información y opiniones y difundirlas sin limitación de fronteras por cualquier medio de expresión, constituyen libertades civiles que son esenciales para el ejercicio normal de los derechos sindicales. 
- La no intervención de los gobiernos en la celebración o el desarrollo de las reuniones sindicales y las autoridades públicas deben abstenerse de toda intervención que pueda evitar este derecho.

- La celebración de reuniones públicas y la presentación de reivindicaciones de orden social y económico constituyen manifestaciones tradicionales de la acción sindical con ocasión del 1 de mayo.

- El derecho a organizar manifestaciones públicas es un aspecto importante de los derechos sindicales.

- El derecho a expresar opiniones por medio de la prensa o en otra forma es uno de los elementos esenciales de los derechos sindicales.

- Una legislación de emergencia establecida contra elementos antisociales o desestabilizadores, no debería utilizarse para sancionar a trabajadores que ejerzan derechos sindicales.

- El artículo 2 del Convenio 87 habla expresamente del derecho de los trabajadores y empleadores «sin ninguna distinción», de constituir las organizaciones que estimen convenientes y de afiliarse a ellas.

- Consagra el principio de la no discriminación en materia sindical y la expresión "sin ninguna distinción», que implica el reconocimiento de la Libertad Sindical sin discriminación de ninguna clase debida a la ocupación, al sexo, al color, a la raza, a la nacionalidad, a las opiniones políticas, etc., no sólo a los trabajadores del sector privado de la economía, sino también a los funcionarios y a los agentes de los servicios públicos en general.

- Las normas del Convenio 87 se aplican a todos los trabajadores "sin ninguna distinción», y por consiguiente, amparan a los empleados del Estado. No es equitativo distinguir entre trabajadores privados y empleados públicos, ya que ambos gozan del derecho a organizarse para defender sus intereses.

- El Comité considera inconveniente e incompatible la disposición legal de unos Estados de exigir el 50\% de empleados para formar un sindicato, y el 50\% de empleados y trabajadores para fundar un sindicato ya que coarta la Libertad Sindical. 
- El principio de la Libertad Sindical podría llegar a ser muchas veces letra muerta si para crear una organización los trabajadores y empleadores tienen que obtener un permiso cualquiera, ya prevista la forma de una licencia para fundar la organización sindical propiamente dicha, de una sanción discrecional de sus estatutos o de su reglamento administrativo o de alguna autorización previa indispensable para proceder a su creación. No obstante, si bien los fundadores de un sindicato tienen que observar los requisitos de publicidad u otros análogos que puedan regir de acuerdo con determinada legislación, tales requisitos no deben equivaler prácticamente a una autorización previa ni constituir un obstáculo para la creación de una organización hasta el punto de constituir en los hechos una prohibición pura y simple. Aun cuando el registro sea facultativo, si de él depende que las organizaciones puedan gozar de los derechos básicos para poder "fomentar y defender los intereses de sus miembros», el mero hecho de que en tales casos la autoridad encargada de la inscripción goce el derecho discrecional de denegarla conduce a una situación que apenas diferirá de aquellas en que se exija una autorización previa.

- Las formalidades previstas por la legislación para constituir un sindicato no deben ser aplicadas en forma que retrasen o impidan la formación de la organización.

- Aun reconociendo que en ciertas circunstancias, puede ser legítimo que el registro confiera a una organización sindical ventajas en cuestiones tales como la representación para fines de negociación colectiva, consultas por parte del gobierno o nombramiento de delegados ante organismos internacionales, en circunstancias normales no debería dar lugar a una discriminación tal que las organizaciones no registradas queden sujetas a medidas especiales de control por parte de la policía que limiten el ejercicio de la Libertad Sindical.

- Cuando se exige el registro del sindicato, y la legislación interna de un Estado lo exige discrecionalmente como requisito, éste se constituye en autorización previa lo cual es un obstáculo a la Libertad Sindical y la creación de organizaciones sin autorización previa.

- La suspensión por vía administrativa de organizaciones sindicales constituye una grave limitación de los derechos de 
las organizaciones de trabajadores de elegir libremente a sus dirigentes y de organizar su gestión y sus actividades.

- La suspensión por el Ministerio de Trabajo de la personalidad jurídica de los sindicatos - personalidad que constituye un requisito para su funcionamiento legal -, es contrario al principio general aceptado de que los sindicatos no deben ser suspendidos por vía administrativa (que sería el caso del ejecutivo, legislativo, ministro de trabajo).

Por otra parte, como se planteó en líneas anteriores, en la Constitución Nacional colombiana se consagra el principio de la Libertad Sindical en el artículo 39, de igual forma la Jurisprudencia ha indicado que;

«Se concluye que el derecho de asociación sindical es un derecho subjetivo que tiene una función estructural que desempeñar, en cuanto constituye una vía de realización y reafirmación de un Estado social democrático de derecho, más aún cuando este derecho que permite la integración del individuo a la pluralidad de grupos, no constituye un fin en sí mismo o un simple derecho de un particular, sino un fenómeno social fundamental en una sociedad democrática y, es más, debe ser reconocido por todas las personas y órganos del poder público...»

\section{LEGISLACIÓN LABORAL CONTRARIA A LA LIBERTAD SINDICAL}

Tal como lo plantean Buitrago y Restrepo (2015), la jurisprudencia de la Corte Constitucional colombiana, ha desarrollado el derecho a la Libertad Sindical, protegiendo su creación y consolidación frente a la intervención del empleador, y está acorde con las disposiciones internacionales, convenios y tratados en los cuales Colombia hace parte, reconociendo no solo el derecho de las personas naturales sino jurídicas, en tanto, que la protección recae en el derecho fundamental que tienen las personas como también las agremiaciones sindicales, a poder asociarse, promulgar y divulgar todos los derechos que tienen los trabajadores, sin ninguna restricción por parte del empleador porque en este evento, se estaría vulnerando un derecho fundamental reconocido constitucionalmente, no obstante tal protección se torna insuficiente, ya que falta regulación concreta por parte del Congreso de la República, mayor seguridad para los dirigentes sindicales frente a la violencia selectiva de la que son víctimas y es urgente iniciar un diálogo que logre la concertación entre pa- 
trono-empleado y el estado, con las prohibiciones de injerencia legales, pero con una política idónea que garantice el ejercicio de la Libertad Sindical sin restricciones de ningún tipo.

Para Fernández (2015), la Libertad Sindical en Colombia, presenta problemas concretos referidos al derecho de huelga, que se encuentra restringido en la mayoría de los sectores productivos, pese a la protección del legislador y al ya mencionado, bloque de constitucionalidad, y aunque el derecho a la huelga, que es un legítimo instrumento de lucha sindical, es desconocido para los trabajadores de las tres ramas del poder público

Los gobiernos colombianos nunca han presentado oportunamente al Congreso los proyectos de Ley para que sean adoptados los convenios de OIT, pese a la obligación estatutaria que tienen de hacerlo.

Entre los hechos más notorios de violación a la Libertad Sindical por parte de las leyes de trabajo destacan:

El artículo $359^{\circ}$ del Código sustantivo del trabajo (CST) en concordancia con el art. $40^{\circ}$, que exigen un mínimo de 25 trabajadores para fundar una organización sindical, y el hecho de ser causal de disolución tener menos de esos afiliados, esto es constituye en un obstáculo para la constitución de organizaciones sindicales sobre todo frente a pequeños empleadores en los cuales ni siquiera el $100 \%$ de sus trabajadores alcanzan este número.

El artículo $362^{\circ}$ del C.S.T., subrogado por la Ley 50 de 1990 artículo $42^{\circ}$ que prescribe el contenido de los estatutos de la organización sindical vulnerando la soberanía y autonomía del sindicato, esto reglado incluso en Resoluciones del Ministerio del Trabajo que diseñan modelos de Estatutos que sirven de guía al momento de ser registrados por las autoridades laborales.

Los Artículos $365^{\circ}, 366^{\circ}$ y $372^{\circ}$ del CST, subrogados por los artículos 45,46 y 50 respectivamente, de la ley 50 . La realidad es que el Sindicato desde su fundación tiene personería pero, no le sirve para nada porque por los mencionados artículos subsiguientes que establecen que el sindicato sólo a partir de su registro y durante la vigencia de ese registro puede ejercer sus atribuciones sindicales, imponiendo para el registro el mismo trámite que otrora había que surtir para obtener la personería. Se cambió el nombre de personería por el de registro y en la realidad es el registro es el que faculta para actuar válidamente al Sindicato.

Los artículos 359 y 370 del CST, subrogados respectivamente por los artículos 48 y 49 de la Ley 50, con base en los cuales el Ministerio de Trabajo interviene para aprobar la modificación de los Estatutos del sindicato, y esas modificaciones tienen validez solo a partir de su 
registro constituyendo un control previo e interferencia a la autonomía sindical.

El artículo 371 del CST, que prevé que cualquier cambio en la junta directiva del sindicato, para que surta efecto legal, debe haberse notificado y autorizado por el Ministerio de Trabajo mediante resolución lo cual se presta para manipulaciones y como obstrucción de la Libertad Sindical.

El artículo 380 del CST, establece la interdicción para ejercer el derecho de asociación sindical, como sanción para el trabajador hasta por un lapso de 3 años, lo cual implica la pérdida del derecho de asociación.

Los artículos $384^{\circ}, 388,422^{\circ}$ y $432^{\circ}$ del CST que imponía límites a la Libertad Sindical de los trabajadores extranjeros en cuanto a la proporcionalidad de más de dos terceras partes de trabajadores colombianos con respecto de los extranjeros para fundar sindicatos, en cuanto a la imposibilidad de los extranjeros de pertenecer a las juntas directivas de los sindicatos, de las federaciones o confederaciones y frente a la imposibilidad de ser designados como negociadores, estas limitaciones fueron eliminadas cuando se preparaba este documento por fallo de la Corte Constitucional sentencia C - 385 del 5 de abril del 2000, que elimina estas discriminaciones en razón de la nacionalidad que desde hace 50 años existían en la legislación laboral colombiana, dejando claro que este avance no se produce por voluntad del Gobierno Nacional ni del Legislativo sino por una acción pública ciudadana que es acogida originando este fallo.

El artículo 388 del CST, que establece prerrequisitos para pertenecer a la junta directiva del sindicato en lo que tiene que ver con la antigüedad en el empleo.

El artículo 416 del CST, que expresamente prohíbe a los empleados públicos ejercer el derecho a la contratación colectiva y prohíbe a estos mismos ejercer el derecho a la huelga. Lo cual se mantiene pese a existir la Ley 411 del 5 de noviembre de 1997 por la cual se aprueba el Convenio 151 de OIT sobre negociación colectiva en el sector público. El Gobierno Nacional se niega a dar aplicación a esta norma.

El artículo 429 del CST, que no prevé sino una forma de huelga, que es la suspensión pacífica de las labores y dentro del marco del conflicto colectivo para presionar la negociación colectiva, desconociendo otras formas de huelga, como la operación tortuga, las huelgas de solidaridad, las huelgas nacionales, las huelgas para hacer cumplir las convenciones colectivas de trabajo entre otras.

El artículo 430 del CST, que al definir como servicio público una serie de servicios no esenciales impide que vastos sectores de trabajadores no ejerzan el derecho a la huelga.

El artículo 444 del CST, subrogado por el Artículo 61 de la ley 50, Qué impone la intervención del Ministerio en la votación de los tra- 
bajadores de la huelga o de la solicitud de convocatoria de tribunal de arbitramento, siendo una injerencia en la autonomía sindical.

El artículo 445 del CST, subrogado por el artículo 62 de la Ley 50, que limita la iniciación de la huelga a no antes de dos ni más de diez días después de votada reduciendo la autonomía y el impacto por el ejercicio oportuno u autónomo de este derecho.

El artículo 448 del CST, subrogado por el artículo 63 de la Ley 50, numerales 3 y 4, que autoriza al Ministerio de Trabajo para entrometerse en los asuntos de los trabajadores convocando asambleas tendientes a parar la huelga y convocar a Tribunal de Arbitramento Obligatorio. También después de 60 días de huelga, el Ministerio de Trabajo de manera discrecional tiene la facultad de imponer un Tribunal de Arbitramento y suspender la huelga, más grave si se tiene en cuenta que no existen causales predeterminadas en la ley, por tanto esta facultad es a criterio subjetivo del Ministro de Trabajo de turno.

El artículo 450 del CST, subrogado por el artículo 65 de la ley 50, sobre la ilegalidad de la huelga, con causales como la de realizarse en un servicio público, o por tener fines distintos a los profesionales, esa ilegalidad contiene la autorización para despedir, la pérdida del fuero sindical, las sanciones para la organización sindical y para los trabajadores responsables de la huelga.

El derecho a la huelga, que es un legítimo instrumento de lucha sindical, es desconocido para los trabajadores de las tres ramas del poder público, en la banca, el transporte, la salud, la industria del petróleo los servicios públicos domiciliarios y en otras áreas de la producción consideradas de servicio público.

El artículo 451 CST Que faculta al Ministerio del Trabajo para declarar administrativamente la ilegalidad de un paro colectivo, sumado a que ese acto no tiene recursos por la vía gubernativa, y se debe iniciar es una acción ordinaria ante la jurisdicción del Contencioso Administrativo que puede tardar varios años en resolverse, es decir no hay recurso contra la arbitrariedad y parcialidad que en muchos conflictos colectivos asume el Ministerio de Trabajo.

El artículo 452 CST subrogado por el artículo 34 del Decreto 2351/65, al igual que la ley 48 de 1968, art. 3, qué imponen el arbitramento obligatorio a los trabajadores de los servicios públicos, y a los trabajadores en huelga que a juicio del Presidente afecte los intereses de la economía nacional.

El decreto 2351/65 Art. 40 subrogado por la Ley 50, artículo 67, que facilita los despidos colectivos al arbitrio del patrono, y que le da una tabla porcentual a los patronos para que dentro de ese margen hagan despidos sin quedar incursos en sanciones por despidos colectivos.

En el Informe de la Comisión de Aplicación de Normas de la OIT (2000), ha señalado como normas contrarias con el Convenio 87 los 
artículos 380,3 del CST (suspensión hasta por tres años, con privación de los derechos de sindicación, de los dirigentes responsables de la disolución de un sindicato);

La prohibición de la huelga en servicios públicos no necesariamente esenciales, prohibición de la huelga a las federaciones y confederaciones.

La facultad del Ministro de Trabajo de someter de oficio a consideración de los trabajadores, una vez declarada la huelga por el sindicato, La voluntad de someter las diferencias a un tribunal de arbitramento; La facultad del Ministro para someter el diferendo a tribunal de arbitramento obligatorio cuando una huelga se prolonga por más de 60 días calendario; La posibilidad legal de despedir a los dirigentes sindicales y sindicalistas que hayan intervenido en una huelga ilegal.

\section{CONCLUSIONES}

Según el análisis expuesto por Zapata (2003), de la crisis del sindicalismo en América Latina debe encuadrarse en (a) el marco general de los antecedentes de lo que son las bases del poder sindical y (b) en el contexto de las dos transiciones antes mencionadas. Ambas dimensiones pueden contribuir a comprender mejor las razones por las cuales el sindicalismo latinoamericano se encuentra hoy en crisis. Siendo estos dos elementos los temas específicamente ligados a la crisis del sindicalismo latinoamericano contemporánea.

La realización del derecho de sindicalización y la actividad sindical sigue siendo de alto riesgo para las y los trabajadores colombianos a pesar del acuerdo de paz con las Fuerzas Armadas Revolucionarias de Colombia (FARC), ya que persiste la actuación de grupos armados ilegales, alta impunidad, persecución empresarial y debilidad estatal para la protección.

Analizando la violencia antisindical en este periodo, se pueden identificar estás características:

i) la tendencia decreciente en el registro de casos;

ii) la violencia antisindical focalizada en activistas y dirigentes sindicales;

iii) se acrecientan los hechos de violencia dirigidos contra organizaciones sindicales en su conjunto; 
iv) se presenta un cruce entre la violencia y la criminalización de la acción sindical;

v) la reactivación de la violencia antisindical en el sector rural;

vi) la persistencia de la violencia antisindical en medio de un contexto de violencia contra líderes y defensores de derechos humanos;

vii) la ausencia de justicia es preponderante;

viii) las medidas dispuestas para proteger a sindicalistas no logran garantizar su Libertad Sindical y su integridad física.

La superación de la violencia antisindical, la disminución de los altos índices de impunidad que la encubre y la ampliación de garantías para la protección a sindicalistas, aunque no son demandas nuevas del sindicalismo, han suscitado duros debates en los últimos años en Colombia. Persiste la deuda del Gobierno en la salvaguardia de la Libertad Sindical, enfrentar la violencia antisindical y perseguir sus promotores y los autores, de manera sistemática y estructurada.

Pese a las numerosas recomendaciones de organismos internacionales, entre ellas la OIT, el PNUD y la Organización para la Cooperación y el Desarrollo Económicos (OCDE) se han ratificado compromisos e implementado algunas medidas por parte del Gobierno en el marco del Plan de Acción Laboral (PAL) suscrito con los EEUU y la Hoja de Ruta (Resolución 2628) acordada con la UE. Colombia está lejos de cumplir esos acuerdos y los esfuerzos realizados han generado avances parciales, pero su impacto en la transformación de la cruda realidad que viven las organizaciones sindicales aún no muestra los resultados esperados.

La crisis del empleo asalariado, los cambios en las formas de contratación, las restricciones normativas al derecho de asociación y en general la existencia de grandes trabas al ejercicio de la Libertad Sindical, han excluido del diálogo social, en materia laboral, a la mayoría de los trabajadores y trabajadoras colombianos. La época donde un mayor porcentaje de la población ocupada llegó a pertenecer a un sindicato $(13,8 \%)$, fue a principios de la década de los setenta, en pleno auge del modelo de sustitución de importaciones y cuando el país había consolidado una importante base industrial. A partir de la década de los ochenta hubo un descenso drástico de esta tasa de sindicalización que continuó en la década de los noventa con el proceso de apertura económica, aunque a menor ritmo. Esta ten- 
dencia descendente no se ha interrumpido al punto que para 2009 se calcula que alrededor de sólo un 4,5\% del total de ocupados del país, se encontraba afiliado a un sindicato.

Este debilitamiento en lo concerniente a la densidad sindical ha tenido continuidad durante este siglo y ha influido notoriamente a la paralización de los indicadores que hacen referencia a la cobertura de la negociación colectiva.

A la escasa participación de los trabajadores en las acciones sindicales se hace necesario sumarle la persistencia de la violencia contra sindicalistas. Según datos de la ENS (Escuela Nacional Sindical), las violaciones a las libertades sindicales entre 2008 y 2009 pasaron de 763 a 707, lo que equivale a una reducción porcentual del 7,3\%. Cabe resaltar que los tipos de violencia más graves, como los homicidios, los desplazamientos y las amenazas, se redujeron levemente en los últimos dos años, disminuyendo su participación dentro del total de violaciones. Sin embargo, los hostigamientos aumentaron de forma considerable.

De igual forma, queda ampliamente argumentado que la Corte Constitucional en su función de máxima intérprete autorizada de la Carta Política colombiana, propende por la protección a la Libertad Sindical, señalando que su condición de derecho fundamental, exige del estado colombiano no solo garantías sino también protección frente a posibles vulneraciones por parte de empleadores, sean estos de carácter público o privado y para lograr la consolidación proteccionista referida, es necesario blindar a los trabajadores sindicalizados del despido, mediante la investidura del fuero sindical. No obstante, el empleador colombiano, suele encontrar mecanismos legales para transgredir el objeto de protección constitucional: la Libertad Sindical, y en la mayoría de los casos, consigue la autorización de despido para estos trabajadores, amparado en las justas causas legales de terminación unilateral del contrato de trabajo, desdibujando la función del fuero a esta clase de trabajadores y desincentivando indirectamente la creación y/o consolidación de sindicatos; vulnerando además, el derecho constitucionalmente consagrado de Libertad Sindical.

Debe sumarse a esto una serie de obstáculos normativos y prácticos que restringen seriamente el derecho de asociación y le impiden a los trabajadores, particularmente a quienes no gozan de un contrato de trabajo tradicional, organizarse para reclamar sus derechos. Existe, sin lugar a dudas, una deuda pendiente por resolver con los trabajadores colombianos: se debe consolidar un diálogo social in- 
cluyente para poder impulsar los cambios necesarios para lograr una mejor distribución del ingreso, generar aumentos en la productividad, avanzar hacia relaciones laborales más armónicas y llevar la democracia a los distintos espacios del mundo del trabajo.

Otras situaciones enfrentan los trabajadores colombianos, poco alentadoras: las nuevas formas de inserción laboral se ha afectado el diálogo social, con la reestructuración de empresas públicas se desmontaron muchas de las conquistas logradas por los trabajadores a través de convenciones colectivas.

Las relaciones de trabajo se han individualizado, la tasa de sindicalización ha descendido continuamente a partir de la segunda mitad de la década de los setenta hasta alcanzar un 4,5\% del total de trabajadores (ENS, 2009) y la disminución de la representatividad de los sindicatos ha cedido paso al protagonismo de otros actores, como la misma Corte Constitucional.

No hay dudas que ante el panorama que vive Colombia es perentorio convertir el trabajo en un factor de integración social. Cabe destacar que según cifras del Departamento Administrativo Nacional de Estadística (DANE), para el mes de abril de 2020, la tasa de desempleo del total nacional fue 19,8\%, lo que significó un aumento de 9,5 puntos porcentuales frente al mismo mes del año pasado $(10,3 \%)$. La tasa global de participación se ubicó en $51,8 \%$, lo que representó una reducción de 10,4 puntos porcentuales frente a abril del $2019(62,2 \%)$. Finalmente, la tasa de ocupación fue 41,6\%, presentando una disminución de 14,2 puntos porcentuales respecto al mismo mes del $2019(55,8 \%)$.

La reconstrucción de un sindicalismo más incluyente y menos hostigado por el entorno social y político exige el reconocimiento de nuevos perfiles de trabajador y de nuevas subjetividades en el mundo del trabajo.

Según el Sistema de Información Sindical de Medellín (2010), entre 1998 y 2009, Colombia acumuló el 63\% de los homicidios de sindicalistas ocurridos en el mundo, seguida muy de lejos, por Filipinas (aproximadamente el 5\%) y Guatemala (aproximadamente el $3 \%$ ). "La más grave, grosera e inadmisible violación de la Libertad Sindical es el homicidio del sindicalista. Hace años, muchos años ya, que esta lesión de la Libertad Sindical se perpetra de manera masiva y continua en Colombia. Hubo años en que fueron cientos los sindicalistas asesinados, al punto que cuando la cifra bajó de tres a dos dígitos, el hecho llegó a ser manejado como un progreso por representantes del Gobierno de ese país". 
De acuerdo al seguimiento adelantado por la ENS, durante el periodo 2012 - 2017 se han presentado alrededor de 2.220 violaciones a los derechos a la vida, la libertad y la integridad cometidas contra sindicalistas en Colombia, de los cuales 143 han sido homicidios. También es necesario anotar que el incremento del 37,0\% de la violencia antisindical presentado en el año 2016 con relación al año 2015 , es un indicador de la persistencia del riesgo para las y los sindicalistas.

A la persistente violencia antisindical, se suma la situación de criminalización de la acción sindical, entendida como el conjunto de acciones que privilegian un tratamiento judicial y de orden público de los conflictos laborales y las actividades sindicales buscando constreñir el activismo sindical y reducirlo a su mínima expresión.

$\mathrm{Al}$ respecto, se encuentra que entre los años 2012 y 2017 la criminalización se ha presentado en distintos ámbitos:

i) 161 protestas laborales y sindicales fueron restringidas por la acción del Escuadrón Móvil Antidisturbios (ESMAD).

ii) Se tiene información de 86 casos en los que sindicalistas enfrentan procesos disciplinarios y judiciales

iii) 210 violaciones contra sindicalistas, fueron cometidas presuntamente por organismos estatales (ejército y policía). Estas acciones en su conjunto son graves porque la acción y la protesta sindical, inclusive la huelga, son tratadas como delitos y no como derechos.

Sigue existiendo una gran brecha entre las necesidades de protección de los sindicalistas y los sindicatos y las medidas implementadas por el gobierno. El programa que opera actualmente la protección y las garantías para la realización de la actividad sindical sigue siendo insuficiente e inadecuado, presenta falencias estructurales en su formulación, efectividad y seguimiento, pero ante todo carece de articulación con una política pública de protección para las personas sindicalizadas y las organizaciones sindicales, que aún no existe.

El Tribunal Mundial de Libertad Sindical, (Mena, 2012), ha señalado al Estado colombiano "por ser responsable de los hechos sistemáticos de violación del principio de Libertad Sindical, en calidad de autor directo, coautor, cómplice o encubridor de homicidios, lesiones, torturas, privaciones ilegítimas de la libertad, atentados, amenazas, despidos y represalias con motivo del ejercicio de la actividad". 
Según el Instituto de estudios para el Desarrollo y la Paz (INDEPAZ), entre enero y noviembre de 2018 en Colombia fueron asesinados 226 líderes defensores de Derechos Humanos en distintas regiones del país, principalmente en aquellas priorizadas por el postconflicto. Allí la ausencia estatal y el vacío dejado por las FARC permiten disputas territoriales por minería ilegal, explotación maderera ilegal, agricultura extensiva, control social y organizativo.

En lo que tiene que ver con el año 2019, según el Sistema de Información de Derechos Humanos, SINDERH, entre el 1 de enero y el 05 de diciembre se han registrado al menos 136 violaciones a la vida, la libertad y la integridad física cometidas contra sindicalistas en Colombia, entre ellas 13 homicidios, 107 amenazas, 10 hostigamientos, un caso de secuestro, un caso de tortura y dos atentados contra la vida. El 84,55\% del total de estos casos de violencia fueron hombres, el $15,44 \%$ fueron víctimas mujeres y el 77,9\% contra dirigentes y líderes sindicales.

A esto se suma un contexto poco favorable de incumplimientos en la implementación de los Acuerdos de paz y obstáculos que han impedido avanzar en los diálogos con el Ejército de Liberación $\mathrm{Na}$ cional (ELN). Mientras que el Gobierno Colombiano en el informe Examen Periódico Universal presentado en mayo de 2018 señala avances en materia de derechos humanos, los movimientos y organizaciones sociales no presentan un balance tan alentador.

$\mathrm{Al}$ nuevo gobierno le esperan grandes retos en materia de garantía, protección y promoción de los derechos humanos, con especial atención los de aquellas personas que están siendo perseguidas y asesinadas por defender derechos laborales, territorios y medio ambiente, poblaciones, por exigir la restitución de tierras, apoyar la paz, denunciar la corrupción y liderar protestas y movilizaciones sociales.

Según el Programa Somos Defensores, en el transcurso del año 2018 han sido asesinados 90 líderes sociales. Esta lamentable situación ha venido ocurriendo en distintas regiones del país, principalmente en aquellas zonas priorizadas por el postconflicto, donde la ausencia estatal y el vacío dejado por las FARC, permiten disputas territoriales, por minería ilegal, explotación maderera ilegal, agricultura extensiva, control social y organizativo.

El estudio del Centro de Información sobre Empresas y Derechos Humanos, revela que Colombia es uno de los países más peligrosos del mundo para los defensores de derechos humanos que denuncian abusos del sector empresarial, según el informe divulgado 72 de 
ellos fueron asesinados entre 2015 y octubre de 2019, señalando además que 181 defensores sufrieron atentados y que el $76 \%$ de estos casos se produjo en zonas con alta inversión industrial.

Esta violencia también genera un ambiente de vulnerabilidad contra sindicalistas y sindicatos, en el 2018, el 89,4\% de las víctimas de la violencia antisindical han sido líderes/as y directivos/as sindicales quienes venían defendiendo derechos humanos y laborales, exigiendo garantías para realizar su actividad sindical, haciendo denuncias, apoyando la paz, participando en huelgas y protestas. Más grave aún, se alerta sobre el incremento de la violencia antisindical en los últimos tres meses, en este periodo se han registrado más de la mitad de los casos documentados en el 2018. A la permanencia de la violencia antisindical, se suma la criminalización de la acción sindical, esto es, el tratamiento de orden público, judicial y punitivo hacia a la actividad sindical.

La violencia antisindical impide o limita el ejercicio de la Libertad Sindical y la defensa de derechos por parte de las y los trabajadores/as. Más aún cuando se trata del caso colombiano, donde el sindicalismo ha padecido la persecución y la violencia que ningún otro movimiento sindical en el mundo ha vivido. Según el seguimiento realizado por la ENS, desde el 1 de enero de 1973 hasta el 27 de agosto de 2018, se han registrado al menos, 14.771 violaciones a la vida, libertad e integridad cometidas contra sindicalistas. Entre éstas, 3.166 homicidios, 404 atentados contra la vida, 239 desapariciones forzadas, 7.269 amenazas de muerte y 1.900 desplazamientos forzados. De los sindicalistas quienes han perdido su vida, 2.836 son hombres, 330 son mujeres y 921 son dirigentes sindicales.

Siguiendo la tendencia de los últimos años, una lectura preliminar de lo ocurrido en lo que va de 2018 muestra que la amenaza, es el tipo de violencia que presenta mayor recurrencia, representada en el $83,23 \%$ del total de casos registrados, muestra la prevalencia de la violencia no letal, pero que, de igual manera, genera un ambiente de vulnerabilidad adverso para el ejercicio de la actividad sindical, así como para las agendas sociales y políticas ligadas a la misma. Durante el último año, gran parte de los sindicalistas y sindicatos víctimas de amenazas estaban llevando a cabo procesos de defensa de derechos, de la paz y de los territorios, reclamando restitución de tierras y apoyando la campaña presidencial de la Colombia Humana.

Señala, un informe del Instituto de Estudios para el Desarrollo y la Paz (Indepaz) que al cierre del mes de abril de 2020 han sido ase- 
sinados 71 líderes sociales o defensores de derechos humanos. De igual forma, según la Central Unitaria de Trabajadores (CUT), maneja cifras entre enero de 2019 y marzo de 2020 fueron asesinados 4 líderes sindicales; asimismo tiene cuatro intentos de homicidio, un caso de desaparición forzosa y 198 casos de amenazas de muerte. La mayoría de los casos no han sido resueltos y el Gobierno sigue sin combatir eficazmente la cultura de impunidad.

Esta focalización de la violencia contra líderes y directivos sindicales es muy grave, pues conlleva la vulneración de derechos individuales y colectivos, impidiendo el libre ejercicio de la Libertad Sindical y generando daños e impactos en los procesos y las organizaciones.

Adicionalmente, en lo que tiene que ver con la dinámica sectorial de la violencia antisindical, algunos de los sectores más golpeados en el periodo reciente, han sido la educación, la agricultura, otros servicios donde se agrupan directivas de las centrales sindicales, trabajadoras de la seguridad, trabajadoras penitenciarias y trabajadores de organizaciones sociales; y otros sectores como el minero y el de la salud. La reactivación de la violencia en las zonas rurales sigue siendo una constante y es una expresión que podría tener una relación con las dinámicas de la violencia contra líderes y defensores de derechos humanos.

Finalmente, la información relacionada con los presuntos responsables de la violencia cometida contra sindicalistas se tiene que en lo corrido del año 2018 prevalecen los casos en los cuales se señala a paramilitares como responsables, con el 56,52\% de los casos. Este resulta ser un factor de alarma, principalmente, porque aumenta la vulnerabilidad y el riesgo que corren hoy los líderes sociales, sindicales, populares, campesinos, reclamantes de tierras, ambientalistas y defensores de derechos humanos en general. A pesar del crecimiento de éstos hechos de violación de los derechos humanos persiste una alta impunidad y falta de eficacia de los organismos judiciales de investigación y de las autoridades responsables de la seguridad y de la integridad de los líderes y defensores de derechos humanos

Es menester acotar que el Estado colombiano, ha sido denunciado constantemente ante el Comité de Libertad Sindical de la OIT, por la frecuente violación a la garantía del ejercicio del derecho a la Libertad Sindical, estableciéndose las Recomendaciones pertinentes, a fin que se cumpla con lo establecido en el marco normativo y con los Convenios firmados por los Estados signatarios respectivamente. 


\section{BIBLIOGRAFÍA}

ANNER, Mark. "Meeting the Challenges of Industrial Restructuring: Labor Reform and Enforcement in Latin America" en Revista Latin American Politicsand Society, Núm. 50 (2). 2008. 33-65 págs.

Bensusán, Graciela. Los Sindicatos y las Reformas Laborales en América Latina. Universidad Nacional Autónoma de México. Instituto de Investigaciones Sociales. México, 2010.

Blanco Vado, Mario. "La Libertad Sindical en Centroamérica. Su regulación y vigencia efectiva”. 1999.

Buitrago, Adriana y Restrepo, Yanitza. "Libertad Sindical: Una nueva visión desde la jurisprudencia Constitucional Colombiana". Colombia, 2015.

CABrera, Diana. Central Unitaria de Trabajadores (CUT). Colombia, entre los 10 peores países del mundo para los trabajadores. https:// www.lafm.com.co/colombia/colombia-entre-los-10-peores-paisesdel-mundo-para-los-trabajadores. 2020

Código Sustantivo del Trabajo. Derecho de federación. [Documento en línea]. Disponible:http://leyes.co/codigo_sustantivo_del_trabajo/417.htmArtículo417-1delCST).

Colectivo de Abogados «José Alvear Restrepo». "Libertad Sindical y Derechos Humanos en Colombia”. 2005.

Colectivo de Abogados José Alvear Restrepo. “Convención contra la tortura y otros tratos o penas crueles inhumanos o degradantes". 2005.

CONFERENCIA INTERNACIONAL DEL TRABAJo, Octogésima tercera reunión, Ginebra 1996, Actas, Oficina Internacional del Trabajo, primera edición, 1996, página 14/100

CONFERENCIA InTERnACIONAL DEL Trabajo. Informe de la Comisión de Aplicación de Normas. http://ilo.ch/public/spanish/standards/relm/ ilc/ilc86/com-apd3.htm.2000.

CONFEDERACIÓn Sindical InTERnacional. "Informe CSI 2013: Las violaciones de los derechos sindicales en todo el mundo en 2011". 2012.

Consejo Sindical Unitario de América Central y Caribe. "Libre funcionamiento de las organizaciones sindicales: Garantías para su crecimiento y consolidación”. Organización Internacional del Trabajo y ACTRAV, Costa Rica. 2011. 
Constitución Política de Colombia. 1991. Gaceta Constitucional No. 116 de 20 de julio de 1991.

Corte Constitucional. "Constitución Política de Colombia". Actualizada con los Actos Legislativos de 2016. Artículo 39.

Corte Constitucional. "Derecho de Asociación Sindical". Sentencia C-385/00. Colombia, 2000. Disponible en: http://www.corteconstitucional.gov.co/relatoria/2000/C-385-00.htmColombia

Corte Constitucional. "Libertad de expresión y actividad de los sindicatos". Sentencia 434/2011. Colombia, 2011. http://www.corteconstitucional.gov.co/relatoria/2011/T-434-11.htm.

Corte Constitucional. "Comité de Libertad Sindical de la Organización Sindical de la Organización Internacional del Trabajo". Sentencia T-603/03. Colombia, 2003. http://www.corteconstitucional. gov.co/relatoria/2003/T-603-03.htm.

Corte Constitucional. "Reglamenta la acción de tutela". Decreto 2591. Colombia, 1991. https://www.ramajudicial.gov.co/ documents/10635/19479127/DECRETO+2591+DE+1991PDF. pdf/8f3d9967-a77a-496d-adb9-60ec54d7a72f.

Corte Constitucional. "Derecho de Asociación Sindical". Colombia. Sentencia T-261/12. Colombia. 2012. Disponible en: http://www. corteconstitucional.gov.co/relatoria/2012/T-261-12.htm2012.

Corte Constitucional. "Derecho de Asociación Sindical. Legitimación del Sindicato para interponer acción de tutela a favor de sus afiliados". Sentencia T-063/14. Colombia, 2014. http://www.corteconstitucional.gov.co/relatoria/2014/t-063-14.htm.

Corte Constitucional. "Derecho de Asociación Sindical". Sentencia No. T-441/92. Colombia, 1992. Disponible en: http://www.corteconstitucional.gov.co/relatoria/1992/t-441-92.htm.

Corte Constitucional. "Libertad de Asociación Sindical. Protección Constitucional Especial”. Sentencia T-842A/13. Colombia, 2013. http://www.corteconstitucional.gov.co/relatoria/2013/T-842A-13. htm.

Corte Constitucional. "Protección por vía de los derechos fundamentales de los sindicatos y de los trabajadores sindicalizados". Sentencia T-434/11. Colombia, 2011. http://www.corteconstitucional. gov.co/relatoria/2011/T-434-11.htm.

Corte Constitucional. Tratado Internacional Control de constitucionalidad Sentencia No. C-562/92. Colombia, 22 de octubre de mil 
novecientos noventa y dos (1992). https://www.corteconstitucional.gov.co/relatoria/2019/C-248-19.htm

Corte Constitucional. Derecho Internacional. Sentencia No. C-276/93. Colombia, 22 de julio de 1993. http://www.corteconstitucional.gov.co/relatoria/1993/C-276-93.htm.

Corte Constitucional. Derecho de Asociación Sindical. Sentencia C - 385 del 5 de abril del 2000. https://www.corteconstitucional.gov. co/relatoria/2000/C-385-00.htm

Departamento Administrativo Nacional de Estadística (DANE), 2020.https://www.dane.gov.co/index.php/estadisticas-por-tema/ mercado-laboral/empleo-y-desempleo.2020

De La Garza, Enrique. Sindicatos y nuevos movimientos sociales en América Latina. Colecciones Grupos de Trabajo de CLACSO. Buenos Aires. 2005. 61 págs.

Diario El Colombiano. "Van 90 líderes sociales asesinados en 2018 según la ONG Somos Defensores”. El Colombiano, Julio 13 de 2018. http://www.elcolombiano.com/colombia/cuantos-lideres-socialeshan-asesinado-en-colombia-durante-2018-DF8997104

Diario El Tiempo. Van 71 líderes sociales y 20 desmovilizados asesinados este año. https://www.eltiempo.com/justicia/conflicto-y-narcotrafico/cifras-de-lideres-sociales-y-desmovilizados-de-farc-asesinados-en-2020-segun-indepez-480144

Escuela Nacional Sindical. "Violencia antisindical en 2018. Crece la arremetida contra activistas y la dirigencia sindical". Colombia, 2018. http://www.rebelion.org/noticias/2018/9/246157.pdf 2018. 6 págs.

FERNÁNDEZ, Alonso, E. "El Juez laboral y la jurisprudencia constitucional sobre el derecho de asociación" en Revista de Derecho Público. Número 34. Ediciones Uniandes, Bogotá, 2015.

REINHARDT, Nola and PERES, Wilson. "Latin America's new economic model: micro responses and economic restructuring", in World Development. Volumen 28. Número 9. 2000.

LEY 26 DE 1976. "Convenio Número 87. Convenio relativo a la Libertad Sindical y a la protección del derecho de sindicación". Congreso de Colombia, 26 de septiembre de 1976. http://www.suinjuriscol.gov.co/viewDocument.asp?ruta=Leyes/1582563.

MARín Boscán, Francisco. "Consideraciones sobre la Libertad Sindical en América Latina”. Fronesis. Revista de Filosofía Jurídica, 
Social y Política. Vol. 20, No. 2. Instituto de Filosofía del Derecho Dr. J.M. Delgado Ocando. Universidad del Zulia. Venezuela. 2013. 235-251 págs.

Martínez, Daniel y Vega, María. La Libertad Sindical en los países andinos. Primera Edición. Oficina Internacional del Trabajo. 2001.

Mena, Luís Alfonso. "Libertad Sindical en Colombia: una farsa". 2012.

SÁnchez, Marcos; ZegarRa, José; Rodríguez Calderón, Eduardo. Manual para la Defensa de la Libertad Sindical. 4a. ed. (Revisada). Lima: OIT/ Oficina de la OIT para los Países Andinos, 2013. 1-176 págs.

Sistema DE INFORMACIÓn DE DeREchos Humanos. SINDERH. Violencia antisindical en 2018. Crece la arremetida contra activistas y la dirigencia sindical. Colombia, 2018.

Silva R., Marcel. Libertad Sindical y derechos humanos en Colombia. En Colectivo de Abogados «José Alvear Restrepo». 2005.

Touraine, Alain. ¿Qué es la democracia? Buenos Aires. Fondo de Cultura Económica. 1995.

URIARte ERmida, Oscar. "Crítica de la Libertad Sindical". Revista PUCP. Revista de la Facultad de Derecho. 2012.

UPRIMNY, Rodrigo. "El bloque de constitucionalidad en Colombia”. 2005. http://redescuelascsa.com/sitio/repo/DJSBloque_ Constitucionalidad(Uprimny).pdf

Vega Ruíz, María LUZ. "Libertad de asociación, Libertad Sindical y el reconocimiento efectivo del derecho de negociación colectiva en América Latina”. Oficina Internacional del Trabajo, Ginebra. 2004.

Vega Ruíz, María. La Reforma Laboral en América Latina: Quince años después. Un análisis comparado. Oficina Internacional del Trabajo. Lima. 2005. 280 págs.

Zapata, Francisco. ¿Crisis en el Sindicalismo en América Latina? The Helen Kellogg Institute for International Studies, 2003. 
